Complementary Feeding of Breast-fed Children

\title{
Mothers' Knowledge and Practices about Complementary Feeding for their Breast-fed Children at EI Behaira Governorate
}

\author{
Abeer Abd El Azziz Mohamed Madian, Lecturer \\ Community Health Nursing, Faculty of Nursing, Damanhour University \\ Naglaa Kamel Abduallah Hussein, Lecturer \\ Community Health Nursing, Faculty of Nursing, Damanhour University
}

\begin{abstract}
Background: Adequate nutrition is critical to child health and development. Growth during the first year of life is greater than at any other time after birth. Improving infant and young child feeding practices is therefore critical to improved nutrition, health, and development of children. Objective: This study aimed to is to assess mothers' knowledge and practices about complementary feeding for their Breast-fed Children at El Behaira Governorate. Setting: The study was carried out at El Behaira Governorate. Subjects: The study sample included 400 mothers. Tools: Data was collected through face-to-face interviewing questionnaire of mothers' with breast fed children. Results: More than half of the mothers (59\%) knew that the age of six months is the ideal age for starting complementary feeding, despite that it was practiced by $9 \%$ only. The majority of the mothers (95.0\%) knew that the cup and spoon are the correct method for food introduction. However $42.8 \%$ used bottle with teat in feeding their infants the first feed. More than three quarters of the mothers (79.8\%) not able to define complementary feeding as introduction of foods besides breast-feeding. The majority of the mothers (99\%) defined weaning as cessation of breast-feeding. More than half of mothers (59\%) involved in this work knew that the infant should consume 2-3 meals /day at age of 6-8 months which was correct answer. Less than half of mothers obtained poor score of knowledge regarding complementary feeding. Infant and young child feeding practices in this study were scarce. Conclusion: There was general lack of awareness of some major recommended practices regarding complementary feeding. Recommendations: This study recommended implementation of health education program in primary health care settings to improve and support the breastfeeding and complementary feeding practices among mothers. Longer paid maternity leave at least for 6 months and reduction in working hours are also recommended.
\end{abstract}

Keywords: Complementary feeding, exclusively breastfed, Feeding practices. 


\section{Introduction}

The first two years of life are critical stages for a child's growth and development. Infant feeding from birth up to the first years of life influences an individual's whole life $\mathrm{e}^{(1,2)}$. Adequate nutrition during infancy and early childhood is essential to ensure healthy growth and development of children to their full potential. Any damage caused nutritional deficiencies during this period could lead to impaired cognitive development, compromised educational achievement and low economic productivity $^{(3,4)}$.

The World Health Organization has described breast feeding as unequalled way of providing ideal food for the survival, healthy growth and development of infants and young children; it is also an integral part of the reproductive process with important implications for the health of mothers. (WHO \& UNICEF) $)^{(5)}$. Infants are vulnerable during the transition phase from exclusive breast milk to introduction of complementary feeding over and above breast milk. For ensuring the nutritional needs of a young child are met, breastfeeding must continue along with observing the followed practices for appropriate complementary feeding $^{(6,7)}$.

$$
\text { Complementary feeding means }
$$

complementing solid/semi-solid food with breast milk after child attains age of six months, because breast milk is no longer sufficient to meet the nutritional requirements of infants. Therefore, other foods and liquids are needed along with breast milk $^{(8)}$. These foods may be prepared specifically for children, or they may consist of family foods that are served to children ${ }^{(9,10)}$.

According to the World Health Organization (WHO), complementary foods should fulfill the needs of rapidly growing child; and appropriate meaning that foods should be diverse, of appropriate texture and given in sufficient quantity $^{(11)}$. Feeding practices is a critical aspect of caring for infants and young children. These practices stimulate bonding, psycho-social development and lead to improved physical growth, reduced susceptibility to common childhood infections and better resistance to cope with them ${ }^{(12)}$. Inappropriate feeding practices are a major cause of the onset of malnutrition in infants and young children $^{(13,14)}$.

Fault feeding practices including lack of breast feeding and early introduction of solid foods have been reported as children health risks ${ }^{(15)}$. 
The prevalence of breast and complementary feeding differs from one country to another and from one society to another; this of course is due to cultural and religious factors. Mother's practices related to breast feeding and complementary feeding were not optimum and efforts should be done to change their behaviors and reinforce healthy feeding practices $^{(16)}$.

In Maternal and Child Health centers, nurses play an important and vital role, as they contribute in health promotion and disease prevention. They have an important role in teaching women, providing guidance, giving information and counseling about the benefits and management of breastfeeding, and giving a timely; safe; and adequate complementary feeding with continued breast-feeding ${ }^{(17,18)}$.

\section{Aim of the Study}

To assess mothers' knowledge and practices about complementary feeding for their Breast-fed Children at El Behaira Governorate.

\section{$\underline{\text { Research Question: }}$}

What are the mothers' knowledge and practices about complementary feeding for their Breast-fed Children?

\section{Materials and Method}

Materials

Design: A cross-sectional descriptive design was carried out to conduct this study.

Setting: The study was conducted at four Maternal and Child Health centers affiliated to Ministry of Health in El Behaira Governorate, namely, El Halal MCH (Damanhor City), Kafer El-Daowar MCH (Kafer El-Daowar City), El Naser MCH (Abo El Matameer City), and Kom Hamada MCH (Kom Hamada City).

Subjects: 400 mothers attending to wellbaby clinics at $\mathrm{MCH}$ centers were selected from previously mentioned setting to carry out this study according to the following inclusion criteria: Mothers accompanying their breast-fed children aged less than two years and who started complementary feeding.

Sample size:

Sample size was 400 according to $24 \%$ with a precision of $6 \%$, alpha error $=$ 0.05 and design effect $=2$ (cluster design effect), so sample size equal 400 mothers.

\section{Sampling technique:}

Multistage sampling technique was used to select the subject as follow: 
Complementary Feeding of Breast-fed Children

- Four districts were selected randomly using blind paper picking out of 15 districts.

- One center was selected randomly from each district.

- By using equal allocation method 100 mothers were selected randomly from each center.

\section{Method}

Tool: $\quad$ A structured interview questionnaire was designed by the researchers to collect the necessary data from mothers. It included three parts:

\section{Part one:}

1- Concerned with socio demographic characteristics of study subjects including age, sex and birth order of child.

2- Characteristics of the parents included: age, level of education, occupation and socioeconomic level of the family was estimated by using Fahmy and EL- Sherbini $(1983)^{(19)}$.

Part two: It was composed of 3 items to assess mothers' knowledge about:

1- Complementary feeding.

2- Storage of foods \& food preparation.

3- Methods of storing cooked food.

Part three: Concerned with practices of mothers regarding complementary feeding including:

a- The age of starting complementary feeding.

b- Feeding during sickness.

c- Food preparation and storage.

d- Mothers' behaviors regarding feeding their infants.

- Permission to conduct the study was obtained from the administrators of the health affair in El-Beheira Governorate.

- Permission from directors of the selected $\mathrm{MCH}$ centers was obtained.

- Data collection:

1- The researcher was able to interview about $8-10$ mothers daily. Each $\mathrm{MCH}$ center was visited twice / week, on the scheduled day of vaccination, and also at the time of follow up for age one and two years old. Each sheet took 15-20 minutes to be answered. Data was collected from February 2014 till August 2014.

2- Tool of data collection was tested for its content validity and relevance by a jury consisted of three academic staff in Community Health Nursing from 
Complementary Feeding of Breast-fed Children

Alexandria and Damanhour

University.

3- A pilot study was carried out in a center not included in the study. The pilot study included 40 mothers (10\% from total sample), simple modifications were done.

4- Cronbach Alpha Equation used to test the tool reliability (internal consistency of the tool items was $0.79)$.

\section{Ethical considerations:}

The purpose and the nature of the study were clarified to mothers, for full cooperation. The questionnaire sheet was explained to the participants, verbal consent was obtained from each mother. Privacy was maintained during process of collecting data. Confidentiality of mothers' response was guaranteed during the study.

\section{Statistical Analysis}

After collection of data, they were coded and transferred into especially designed formats to be suitable for computer feeding. Following data entry, checking and verifying processes were carried out to avoid any errors during data entry.
Data was analyzed using PC with Statistical Package for Social Sciences (SPSS) version 16.0.

The level of significance selected for this study was 0.05 .

The following statistical measures were used:

A- Descriptive statistics:

Count and percentage: Used for describing and summarizing quantitative data, Arithmetic means Standard deviation (SD) and range were used.

B- Analytical statistics:

Chi square test $\left(\mathrm{X}^{2}\right)$ : it was used to test the association between categories of variables.

Correlation coefficient (rs) was used to test correlation between two quantitative variables not normally distributed.

C- Scoring system:

A) Socioeconomic level of the family was estimated by using Fahmy and ELSherbini (1983). ${ }^{(19)}$ The total socioeconomic score summed 50 and classified to the following levels:

Score

$\begin{array}{lc}\text { - High } & 42.5-50 \\ \text { - Middle } & 37.5-42 \\ \text { - Low middle } & 25-37 \\ \text { - Low } & <25\end{array}$


Complementary Feeding of Breast-fed Children

B) Scoring system for assessing knowledge of mothers regarding complementary feeding, safe preparation and storage of foods; this section consists of 18 items and the correct answers were pre-determined according to the literature. A score of (2) was given to the correct complete answer, a score of (1) for correct but incomplete answer and a score of (0) for the wrong or missed answers. The total knowledge score was obtained for each mother (0-36). Percent of the total knowledge score was calculated as follows;

$$
\begin{array}{ll}
\text { Poor knowledge }<18 & (<50 \%) \\
\text { Satisfactory 18- }<27 & (50-<75 \%) \\
\text { Good } \geq 27 & (\geq 75 \%) \\
\text { C) Scoring system for assessing }
\end{array}
$$
mothers' practices regarding complementary feeding: this section of the questionnaire includes 13 items composed of safe preparation and storage of foods; the items were scoring as following: A score "2" was given to compete correct practice. While, score "1" was given to correct but incomplete practice and a score "0" was given to incorrect or never done. The total practice score was obtained for each participant (026). Percent total practice score was calculated as follows; poor practice <13 (less than 50\%), satisfactory practice
$13-<19.5(50-<75 \%)$ and good practice $\geq 19.5(\geq 75 \%)$.

\section{Results}

Table (1) illustrates that the total studied sample reached 400 mother-child pair; boys represented $52.3 \%$ and girls $47.7 \%$. The mean age of children was $10.7 \pm 4.77$ months and more than one third $(36 \%)$ of them was the second child.

Regarding mothers' age, more than one third $(35.5 \%)$ of the mothers' sample was $25-<30$ years and their mean age was $28.35 \pm$ 5.48. Regarding parents' education, less than half of them (41.7\%) of the mothers and $43 \%$ of fathers had secondary education. The table also shows that the majorities (87\%) of mothers' sample are not working and $13 \%$ are working. Moreover, mothers reported that, more than three quarters $(78.2 \%)$ of them not receiving health education about breast feeding either during antenatal or postnatal period.

As regards to the socio-economic score obtained by the studied sample, figure (1) portray that high socioeconomic level constituted $20.5 \%$ of the sample, middle socio-economic level was $27.0 \%$, low middle was $25.0 \%$ and low socio-economic level constituted $27.5 \%$. 
Table (2) presents that more than half (59\%) of mothers knew the correct age for starting complementary foods of infants. It was also noticed that the majority $(93.5 \%)$ of the mothers stated that breastfeeding should be continued for two years. It was also found that only $0.5 \%$ of mothers defined complementary feeding correctly. The majority (99\%) of mothers defined weaning as cessation of breastfeeing. Only $1.0 \%$ of them were able to define weaning correctly. The table also shows that more than three quarters (78.7\%) of the sample mentioned that, yogurt should be the first food given to the infant at the start of complementary feeding. The majority (95.0\%) of women stated that cup and spoon are the appropriate way of feeding infant aged six months. More than half $(59.0 \%)$ of the women reported that infant should eat 2-3 meals at age of 6- 8 months. Also, mothers' knowledge regarding number of meals required for those aged 12 months where $65.7 \%$ of them reported correct answer. Regarding amount of weaning food at age of $6-8$ months, less than half $(48.0 \%)$ of mothers reported that infant should intake from $2-3$ teaspoon $-1 / 2$ cup.

The table also reveals that about more than one third $(35.8 \%)$ of the sample considered that the age of 12 months is the ideal age of the child to be given ordinary family food. More than one third (38.8\%) of sample didn't know types of foods forbidden to the child under two years old. The table also points out that $73 \%$ of the mothers stated that there is necessity to give vitamins besides complementary feeding.

Table (3) reveals that about $80.3 \%$ of mothers had knowledge about washing their hands before both food preparation and feeding the infant. The majority $(82.5 \%)$ of the mothers stated that the infant's hands must be washed before and after feeding. The majority (98.8\%) of the mothers mentioned that the utensils in which the child eats must be washed with soap and water. As regards the water to be used for drinking and food preparation $65.5 \%$ of the women mentioned boiled water. The table also reveals that the majority $(98.3 \%)$ of the mothers stated that the cooked food should be stored at the refrigerator. Also, $88.7 \%$ of the mothers reported that the left-over food stored at the refrigerator must be warmed before feeding them to the child while $11.3 \%$ stated that left-over food should be thrown and the meal of infant must be fresh and immediately prepared before time of eating. 
Figure (2) shows the mothers' sources of knowledge about complementary feeding. The majority $(85.5 \%)$ of mothers had their information from their relatives and neighbors, and $39.5 \%$ of them gain their knowledge from health team members followed by $10.5 \%$ from mass media and only $7.7 \%$ from reading books or magazines.

Figure (3) shows the mothers' total score of knowledge about complementary feeding. The highest score of mothers $(42.75 \%)$ indicating poor score of knowledge, and $31.5 \%$ of them their knowledge score was satisfactory followed by one quarter of them $(25.75 \%)$ had good score of knowledge. Their mean was $53.18 \pm 15.01$.

Table (4) reveals that, only $9 \%$ of the mothers started complementary feeding their infant age of six month, while more than two thirds $(67.7 \%)$ of them started before the age of three months. It can be noticed that more than two thirds $(65.7 \%)$ of the mothers started with yanson or karawia and $22.5 \%$ of the mothers gave their infants yogurt as the first food. Also more than half $(56.2 \%)$ of the mothers used tea spoon to introduce their foods and $42.8 \%$ of the mothers used the bottle with teat. As regards intervals between introductions of each new complementary food, more than the half $(58.5 \%)$ of mothers had no schedule of introducing of each new food while $19.7 \%$ of the mothers introduced new food every two weeks or more.

The table also reveals that, the majority $(85.7 \%)$ of the mothers breastfed their infants for five times or more / day and nearly three quarters $(74.0 \%)$ of the infants consumed the ordinary family food. The table points out that $43.5 \%$ of the infants consumed two meals/ day. Moreover, about two third $(66 \%)$ of mothers give breast feeding only to their children during illness.

Table (5) reveals that approximately half of mothers $(49.0 \%)$ of the mothers washed their hands before food preparation ,before and after feeding their infants. Nearly, half $(49.7 \%)$ of the mothers washed their infants' hands before and after feeding. All mothers washed the utensils in which the child ate with soap and water. As regards the type of water used for infant drinking and food preparation, the majority of them $(80.3 \%)$ used tap water. It was also noticed that less than one fourth $(23.2 \%)$ of the mothers had store the left-over food from their infants at refrigerators. 
Table (6) presents that three quarters $(75.0 \%)$ of the mothers identify that their infant is hungry through infant crying and the majority (97.3\%) of the mothers identify their infant's satiety by refusal of food. The table also presents that the majority $(88.5 \%)$ of the mothers set with their infants during eating their meal. Moreover $72.3 \%$ of the mothers left their infants with no food if they refused to eat and about three quarters $(76.5 \%)$ of the mothers didn't encourage their infants to eat if they refused the food and only $20 \%$ of mothers use positive verbalization or playing to the infant for encouraging him to eat.

Figure (4) shows total score of the mothers' practices about complementary feeding. The highest score obtained by mothers $(59.1 \%)$ indicating satisfactory score of practices, and $26.4 \%$ of them their practices score was poor, on the other hand, (14.5\%) of them had good score of practices.

Table (7) revealed that, there was no significant difference observed between child birth order and their knowledge and practices. However, there was a negative correlation between birth order of child and practices of mothers (rs=- 0.124).
Table (8) reveals that early introduction of complementary foods decreased by increasing the level of mothers' education as it was three quarters (75.0\%) of primary or preparatory educated mothers practiced early introduction followed by $70.0 \%$ of secondary educated. The percentage of those who started complementary feeding at 6 months was higher among university educated mothers $(11.5 \%)$ compared to $6.7 \%$ among illiterate.

Regarding mothers' occupation, the percentage of those who introduced complementary food early (less than 4 months) was higher among non working mothers $(69.0 \%$ vs. $59.6 \%$ of working mothers). Introduction of complementary food at later age of the child (4-<6 months and at 6 months) was higher among working than non working mothers (30.8\% vs. $22.1 \%$ and $9.6 \%$ vs. $8.9 \%$ respectively). The table also reveals that younger mothers have more tendency for early introduction of complementary foods as it was $73.1 \%$ of mothers aged $<25$ years and decreased to $63.6 \%$ of mothers older than 35 years. The percentage of mothers who introduced complementary food at 6 months was higher among older mothers (13.6\% among >35 years vs. $6.7 \%$ among <25 
years. There is no statistically significant association between infant age at introduction of complementary foods and mothers' age and education.

\section{Discussion}

In recent years, the issue of complementary feeding in developing countries has been receiving increased attention. Poor complementary feeding practices contribute substantially to the widespread multiple micronutrient deficiencies in developing countries ${ }^{(20)}$. Egypt is one of the developing countries in which it needs to support correct complementary feeding practices, therefore this study aimed to assess mothers' knowledge and practices about complementary feeding for their Breastfed Children at El Behaira Governorate.

The present study indicated that the majority of the mothers included in the study received their information regarding complementary feeding from their relatives and neighbors. (Figure 2)

A study done in china $(2010)^{(21)}$ revealed different findings as it was reported that the main source of information on child feeding practices was Maternal and child health clinics.
These differences may be due to cultural differences between developing and developed countries.

Regarding age of mothers in this study, more than one third of the mothers were $25-<30$ years. (table 1 ) It is obvious that women belonging to the age group $15-\leq 25$ showed a significantly higher percentage of exclusive breast feeding compared to older group. This could be explained by the fact that the former has eagerness to perform the act of $\operatorname{motherhood}^{(22)}$. This was consistent with Nkala and Msuya (2011) ${ }^{(23)}$.

Generally, housewives have unlimited time available to breast feed their children. Although, it was observed in the present study that, early introduction of complementary foods was slightly increased among not working mothers which constituted the majority of the studied mothers.(Table 8) It differs from other study in Kingdom of Saudi Arabia (2004) ${ }^{(24)}$ which reported that early introduction of complementary foods increased significantly among employed mothers.

Health education during pregnancy was an important factor that may explain the finding of significant higher 
knowledge among women who were exposed to health education during their antenatal visits versus those who did not perform any visit. In the current study, more than three quarters of them not receiving education about breast feeding either during antenatal or postnatal period.(Table1) This may explained that, the majority of mothers in the current study defined weaning as breastfeeding cessation and only $1 \%$ defined weaning correctly as introduction of assistant food with breastfeeding (Table2) these findings were much lower than that study done in Nigeria $(2006)^{(25)}$ which found that less than half of the mothers defined weaning correctly. In the same concept Amin, Halbas and Abd Al-Qader (2011) $)^{(26)}$ recommended raising the knowledge of Arabian women through proposed policies to promote breast feeding which will expand the awareness of the benefits of breastfeeding to include a larger sample of the community through social clubs and the curricula of schools.

Timely introduction of solid foods remains an important factor for healthy infant growth $^{(27)}$. The premature introduction of complementary food was of great concern in the present study. Even with the efforts of the Egyptian $\mathrm{MOH}$ programs, more than two thirds of mothers in the present study still introduced complementary food before the age of 3 months while only $9 \%$ of them start of complementary food at 6 months of age. (Table 4) Despite, more than half, of the mothers in this study being aware of the WHO recommended time to initiate complementary feeding. (Table 2) These results similar with findings from other developing countries such as Kenya ${ }^{(28)}$. It may be attributed to more than half of mothers in the current study classified as low and low middle socio economic status.(Figure 1) So they had inadequate breast milk, and insufficient nourishment. A review of breast milk volumes and composition among poorly nourished communities indicated that milk volumes were lowest in communities with poor levels of nutrition and poor living conditions ${ }^{(29,30)}$.

It has been found in a previous research conducted in Philippines that education plays a significant role in determining the duration of breastfeeding. Increasing level of education also implies adoption of modern ideas while gradually leading to the dereliction of traditional practices regarding child care, thus, a decrease in the rate of Breast feeding ${ }^{(31)}$. 
Majority of the mothers had the knowledge that the cup and spoon should be used and use of bottles is not recommended. (Table 2) They are vehicles for introduction of germs and they are difficult to be cleaned properly $\left(\right.$ WHO-2011) ${ }^{(5)}$. The present study revealed immense in feeding the infant. However during practices, nearly half of them used bottle with teat in feeding their infants the first feed.(Table 4) This finding is similar to results of Al-Jassir et al. (2006) $)^{(32)}$ as about less than half of lactating mothers in Saudi Arabia cited insufficient milk as a reason for introducing bottle feeding. But this was contradicted with study done in Pakistan $(2007)^{(33)}$ in which a lower bottle feeding rate was reported. It may be attributed to; bottle feeding is easier to be used for early introduction of complementary foods than cup with spoon.

Several authors stated that the best first solid food to be introduced is singlegrain iron-fortified infant cereal mixed with breast-milk, usually rice cereal is offered first because it is the least likely to cause an allergic reaction ${ }^{(34)}$. In the present study, more than two thirds of the mothers were used decoctions such as anise and caraway as a first feed.(Table 4) It differs from a study in Egypt $(2014)^{(35)}$ in which Yogurt and juice were considered suitable main diet for weaned infants by more than two third of women. However, Walkers et al. (2006) ${ }^{(36)}$ reported that cow's milk was considered suitable as the main drink for weaned infants.

More than half of the mothers in the present study knew that the suitable age for starting complementary feeding is after 6 month compared to $44.6 \%$ as reported by Kishore $(2008)^{(37)}$.

Regarding safe preparation and storage of complementary foods the present study revealed that the majority of the mothers had the correct knowledge regarding food hygiene, (Table 3) however a half of them practiced that. (Table 5) Severi et al, (1997) ${ }^{(38)}$ revealed that hands should be kept clean and washed immediately before, during and after food preparation.

Safe water is just as important for food preparation as for drinking. If there is any doubts about the water supply, water must be boiled before adding it to food $^{(39)}$. In the present study despite that about two thirds of the mothers stated that boiled water must be used for child drinking and food preparation,(Table 3) 
the majority of the sample used tap water without boiling. (Table 5) Moreover, current study showed that, nearly one tenth only of the mothers stated that they thrown the left over foods and prepared immediate food to their children. (Table 3) the same percent of mothers reported that in their actual practices in which nearly one tenth of them disposing the remind food. (Table 5) in a study done in Alexandria, Egypt by Fouda $(2000)^{(40)}$ it was reported that about one third of mothers stated that they boiled left over foods before they fed their children. Which corresponding to our study (Table 5) It may be attributed to their lack of their awareness regarding immediate preparation of children food.

WHO recommended increasing fluid intake during illness, including more frequent breastfeeding, and encouraging the child to eat soft, varied, appetizing, favorite foods ${ }^{(20)}$. While in the present study about one tenth only of the mothers agree with that recommendation,(Table 4) this may be attributed to the lack of health education sessions about infant feeding during illness in the maternal and child health centers.

The style of child feeding may be an important determinant of child nutrition and health outcomes ${ }^{(8,9)}$. The present study revealed that the majority of mothers were present with their children during the feeding,(Table 6) this in line with study done in Malawi (2000) ${ }^{(41)}$. It may be attributed to increasing awareness of mothers regarding bonding with her infant during feeding practices. Additionally, nearly three quarters of the sample left the child without food if he refused it; (Table 6) the corresponding figures for Malawi (2000) $)^{(41)}$ was only $20 \%$. Moreover, more than three fourths of the present sample did not encourage their children to eat if they did not want to. (Table 6) A similar study was done in Central Mali (1996) $)^{(42)}$ on introducing complementary foods to the infants. They reported that the majority of mothers did not encourage their infant to eat if they did not want to.

Unfortunately, infant and young child feeding practices worldwide are not optimal. Global monitoring indicates that only $39 \%$ of all infants are exclusively breast-fed, even when the assessment is made in children less than 4 months of age. The timely complementary feeding rate is similarly low with a global average of $60 \%$ in 2012 complementary feeding practices of infant and young child are often inadequate in developing 
countries $^{(43)}$. Egypt is no exception, as the study which have been conducted in different parts of the country indicated that mother's practices related to breast feeding and complementary feeding were not optimum and efforts should be done to change their behaviors and reinforce healthy feeding practices. Also efforts are needed for the training of all health carestaff and the establishment of breastfeeding support groups ${ }^{(44)}$.

\section{Conclusion}

Surprisingly, infant and young child feeding practices in this study were scarce. Mothers had poor score of knowledge and lack of awareness of regarding practices of complementary feeding.

\section{Recommendations}

So, this study recommended implementation of health education program in primary health care settings to improve and support the breastfeeding and complementary feeding practices among mothers. Longer paid maternity leave at least for 6 months and reduction in working hours are recommended. Interventions to improve exclusive breastfeeding should target family and community members and include training of health workers in counseling to resolve breastfeeding problems.

Moreover, the results of this study suggest an urgent need to target breastfeeding education campaigns directed to adolescent girls, young adult girls and newly married women to decrease health risk among children in Egypt.

\section{Acknowledgement}

The authors thank the Directories of the Maternal and Child health centers and their special gratitude goes to the nursing staff Centers for their assistance and valuable information. A word of thanks goes also to the mothers who gave their valuable time and participated in the survey. 
Table (1): Distribution of mothers regarding their socio-demographic characteristics

\begin{tabular}{|c|c|c|}
\hline Socio-demographic characteristics of the family & No $(n=400)$ & $\%$ \\
\hline \multicolumn{3}{|l|}{ Child age (months) } \\
\hline $\begin{array}{l}6- \\
9- \\
12-24\end{array}$ & $\begin{array}{l}144 \\
110 \\
146\end{array}$ & $\begin{array}{l}36.0 \\
27.5 \\
36.5\end{array}$ \\
\hline \multicolumn{3}{|l|}{ Mean $=10.7 \pm 4.77$} \\
\hline \multicolumn{3}{|l|}{ Child sex } \\
\hline $\begin{array}{l}\text { Boys } \\
\text { Girls }\end{array}$ & $\begin{array}{l}209 \\
191 \\
\end{array}$ & $\begin{array}{l}52.3 \\
47.7 \\
\end{array}$ \\
\hline \multicolumn{3}{|l|}{ Child Birth order } \\
\hline $\begin{array}{l}\text { Single } \& 1^{\text {st }} \text { child } \\
2^{\text {nd }} \text { child } \\
3^{\text {rd }} \text { child } \\
4^{\text {th }} \text { child } \\
5^{\text {th }} \text { child \& more }\end{array}$ & $\begin{array}{l}141 \\
144 \\
79 \\
22 \\
14\end{array}$ & $\begin{array}{r}35.3 \\
36.0 \\
19.7 \\
5.5 \\
3.5 \\
\end{array}$ \\
\hline \multicolumn{3}{|l|}{ Mother's age (years) } \\
\hline $\begin{array}{l}15- \\
20- \\
25- \\
30- \\
35- \\
40 \& \text { more }\end{array}$ & $\begin{array}{l}10 \\
109 \\
142 \\
95 \\
30 \\
14\end{array}$ & $\begin{array}{r}2.5 \\
27.3 \\
35.5 \\
23.7 \\
7.5 \\
3.5 \\
\end{array}$ \\
\hline \multicolumn{3}{|l|}{ Mean $=28.35 \pm 5.48$} \\
\hline \multicolumn{3}{|l|}{ Mother's education } \\
\hline $\begin{array}{l}\text { Illiterate or read \&write } \\
\text { Literate/Primary } \\
\text { Preparatory } \\
\text { Secondary } \\
\text { University }\end{array}$ & $\begin{array}{l}89 \\
38 \\
54 \\
167 \\
52 \\
\end{array}$ & $\begin{array}{r}22.3 \\
9.5 \\
13.5 \\
41.7 \\
13.0 \\
\end{array}$ \\
\hline \multicolumn{3}{|l|}{ Mother's occupation } \\
\hline $\begin{array}{l}\text { House wives } \\
\text { Working }\end{array}$ & $\begin{array}{l}348 \\
52\end{array}$ & $\begin{array}{l}87.0 \\
13.0\end{array}$ \\
\hline \multicolumn{3}{|l|}{ Father's education } \\
\hline $\begin{array}{l}\text { Illiterate or read \&write } \\
\text { Literate / Primary } \\
\text { Preparatory } \\
\text { Secondary } \\
\text { University }\end{array}$ & $\begin{array}{l}90 \\
29 \\
58 \\
172 \\
51 \\
\end{array}$ & $\begin{array}{r}22.5 \\
7.3 \\
14.5 \\
43.0 \\
12.7 \\
\end{array}$ \\
\hline \multicolumn{3}{|l|}{ Father's occupation } \\
\hline $\begin{array}{l}\text { Not working } \\
\text { Working }\end{array}$ & $\begin{array}{l}5 \\
395\end{array}$ & $\begin{array}{r}1.3 \\
98.7 \\
\end{array}$ \\
\hline \multicolumn{3}{|l|}{ Mothers receiving health education about breast feeding } \\
\hline $\begin{array}{l}\text { Yes } \\
\text { No } \\
\end{array}$ & $\begin{array}{l}87 \\
313 \\
\end{array}$ & $\begin{array}{l}21.8 \\
78.2 \\
\end{array}$ \\
\hline
\end{tabular}




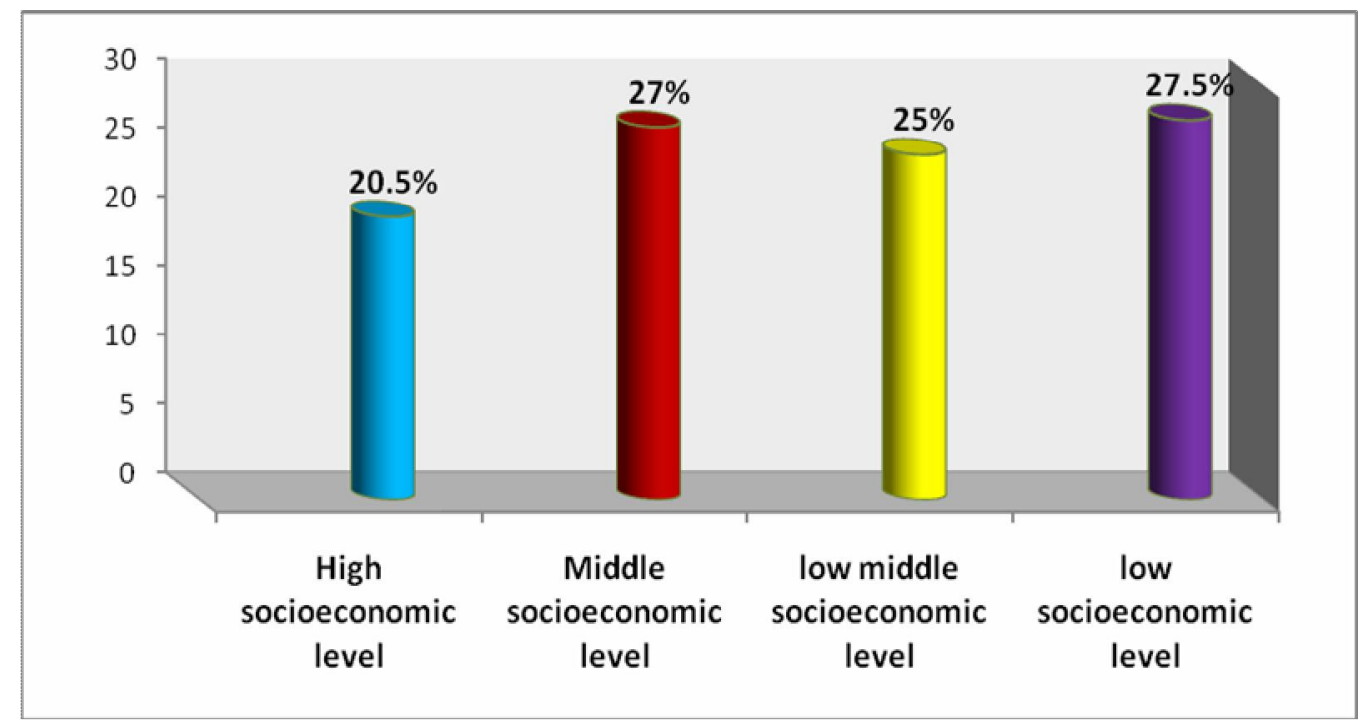

Figure (1): Socio-demographic score of studied sample 
Complementary Feeding of Breast-fed Children

Table (2): Distribution of mothers regarding their correct knowledge about complementary feeding.

\begin{tabular}{|c|c|c|}
\hline Knowledge items & $\begin{array}{c}\text { No } \\
(n=400)\end{array}$ & $\%$ \\
\hline $\begin{array}{l}\text { Age of starting of complementary feeding } \\
\text { - Incorrect ( } 2,3,7 \text { months }) \\
\text { - Correct } 4-6 \text { months }\end{array}$ & $\begin{array}{l}164 \\
236\end{array}$ & $\begin{array}{l}41.0 \\
59.0\end{array}$ \\
\hline $\begin{array}{l}\text { Period of breast feeding } \\
\text { - Incorrect ( } 12 \text { months }-18 \text { months }) \\
\text { - } \quad \text { Correct }(2 \text { years })\end{array}$ & $\begin{array}{c}26 \\
374\end{array}$ & $\begin{array}{c}6.5 \\
93.5\end{array}$ \\
\hline $\begin{array}{l}\text { Definition of complementary feeding } \\
\text { - Incorrect (start feeding at } 1 \text { or } 2 \text { years ) } \\
\text { - Correct (introduction of foods beside breast feeding gradually \&at } 6 \\
\text { months) } \\
\text { - Don't know }\end{array}$ & $\begin{array}{c}319 \\
2 \\
79\end{array}$ & $\begin{array}{c}79.8 \\
0.5 \\
19.7\end{array}$ \\
\hline $\begin{array}{l}\text { Definition of weaning } \\
\text { - Incorrect (cessation of breast feeding) } \\
\text { - Correct (gradual addition of solid foods to the infant's diet and gradual } \\
\text { diminution of breast feeding) }\end{array}$ & $\begin{array}{c}396 \\
4\end{array}$ & $\begin{array}{c}99.0 \\
1.0\end{array}$ \\
\hline $\begin{array}{l}\text { First type of food given to the infant } \\
\text { - Incorrect (yogurt) } \\
\text { - Correct (mahalabia- cereals) }\end{array}$ & $\begin{array}{c}315 \\
85\end{array}$ & $\begin{array}{l}78.7 \\
21.3\end{array}$ \\
\hline $\begin{array}{l}\text { Ways used to introduce food } \\
\text { - Incorrect (using bottles with teat ) } \\
\text { - Correct (cup and spoon) } \\
\end{array}$ & $\begin{array}{c}20 \\
380 \\
\end{array}$ & $\begin{array}{r}5.0 \\
95.0\end{array}$ \\
\hline $\begin{array}{l}\text { Frequency of complementary feeding } \\
\text { considered to infant aged 6-8 months } \\
\text { - Incorrect ( one meal }-4 \text { meals }-5 \text { meals }) \\
\text { - Correct }(2-3 \text { meals / day) } \\
\end{array}$ & $\begin{array}{l}164 \\
236\end{array}$ & $\begin{array}{l}41.0 \\
59.0\end{array}$ \\
\hline $\begin{array}{l}\text { Amount of weaning food at age of } 6 \text { - } 8 \text { months } \\
\text { - Incorrect }(1 / 2 \text { cup }-1 \text { cup }) \\
\text { - Correct }(2-3 \text { tbsf }-1 / 2 \text { cup }) \\
\text { - Don't know } \\
\end{array}$ & $\begin{array}{c}199 \\
192 \\
9 \\
\end{array}$ & $\begin{array}{r}49.7 \\
48.0 \\
2.3 \\
\end{array}$ \\
\hline \multicolumn{3}{|l|}{ Meal frequency after age of 12 months } \\
\hline $\begin{array}{l}\text { - Incorrect ( 2-3 meals / more than } 6 \text { meals / day ) } \\
\text { - Correct (3-4 meals / day) } \\
\text { - Don't know }\end{array}$ & $\begin{array}{c}128 \\
263 \\
9\end{array}$ & $\begin{array}{c}32.0 \\
65.7 \\
2.3\end{array}$ \\
\hline \multicolumn{3}{|l|}{ Ideal age of introduction of ordinary family food/months } \\
\hline $\begin{array}{ll} & \text { Incorrect ( } 6 \text { month }-18 \text { month }-3 \text { years) } \\
\text { - } & \text { Correct (at one year of age) }\end{array}$ & $\begin{array}{l}257 \\
143 \\
\end{array}$ & $\begin{array}{l}64.2 \\
35.8 \\
\end{array}$ \\
\hline \multicolumn{3}{|l|}{ Foods forbidden to child under two years old } \\
\hline $\begin{array}{l}\text { - Incorrect ( fish - meat - chicken ) } \\
\text { - Correct (spicy- fatty food -sweets) } \\
\text { - Don't know }\end{array}$ & $\begin{array}{c}51 \\
194 \\
155 \\
\end{array}$ & $\begin{array}{l}12.8 \\
48.4 \\
38.8 \\
\end{array}$ \\
\hline $\begin{array}{l}\text { Importance of vitamins beside complementary food } \\
\text { - Incorrect (no importance of vitamin) } \\
\text { - Correct (necessity to give vitamins besides complementary) feeding } \\
\text { - Don't know }\end{array}$ & $\begin{array}{c}99 \\
292 \\
9\end{array}$ & $\begin{array}{c}24.7 \\
73.0 \\
2.3\end{array}$ \\
\hline
\end{tabular}


Complementary Feeding of Breast-fed Children

Table (3): Distribution of mothers regarding to their correct knowledge about safe preparation and storage of complementary foods.

\begin{tabular}{|c|c|c|}
\hline Knowledge items & $\begin{array}{l}\text { No }(n \\
=400)\end{array}$ & $\%$ \\
\hline $\begin{array}{l}\text { Timing of washing mother's hands } \\
\text { - Incorrect ( after feeding of infant only) } \\
\text { - Correct (before food preparation and after feeding of child ) }\end{array}$ & $\begin{array}{c}79 \\
321\end{array}$ & $\begin{array}{l}19.7 \\
80.3\end{array}$ \\
\hline $\begin{array}{l}\text { Timing of washing infant's hands } \\
\text { - Incorrect (after feeding only) } \\
\text { - } \quad \text { Correct (before and after feeding ) }\end{array}$ & $\begin{array}{c}70 \\
330\end{array}$ & $\begin{array}{l}17.5 \\
82.5\end{array}$ \\
\hline $\begin{array}{l}\text { Method of washing feeding utensils } \\
\text { - Incorrect (rinsing with water only) } \\
\text { - Correct (with soap and water) }\end{array}$ & $\begin{array}{c}5 \\
395\end{array}$ & $\begin{array}{c}1.2 \\
98.8\end{array}$ \\
\hline $\begin{array}{l}\text { Water to be used for drinking \& food preparation } \\
\text { - Incorrect (tap water) } \\
\text { - } \quad \text { Correct (boiled water) }\end{array}$ & $\begin{array}{l}138 \\
262\end{array}$ & $\begin{array}{l}34.5 \\
65.5\end{array}$ \\
\hline $\begin{array}{l}\text { Method of storing cooked food } \\
\text { - Incorrect (at room temperature) } \\
\text { - Correct (in refrigerator) }\end{array}$ & $\begin{array}{c}7 \\
393\end{array}$ & $\begin{array}{c}1.7 \\
98.3\end{array}$ \\
\hline $\begin{array}{l}\text { Left-over refrigerated food should be } \\
\text { - Incorrect (warmed before using it) } \\
\text { - Correct (left-over food should be thrown) }\end{array}$ & $\begin{array}{c}355 \\
45\end{array}$ & $\begin{array}{l}88.7 \\
11.3\end{array}$ \\
\hline
\end{tabular}




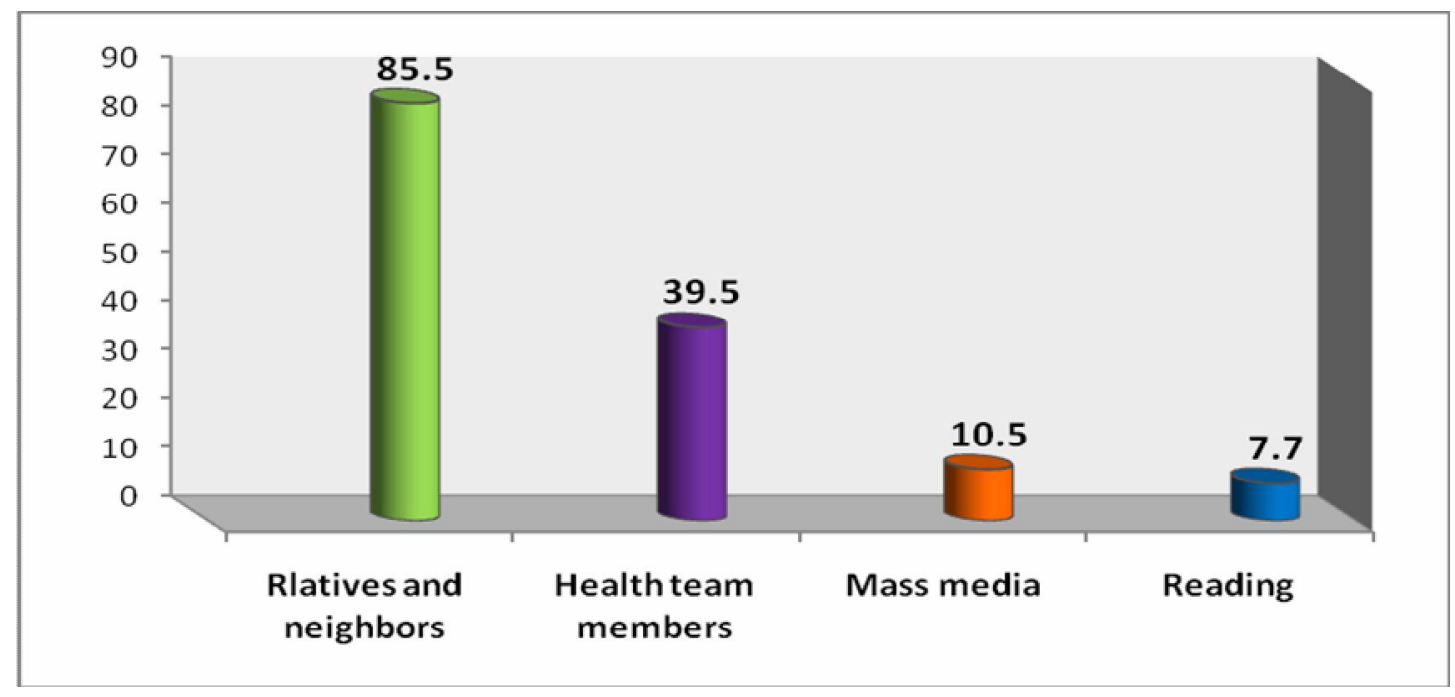

Figure (2): Sources of mothers' knowledge about complementary feeding.

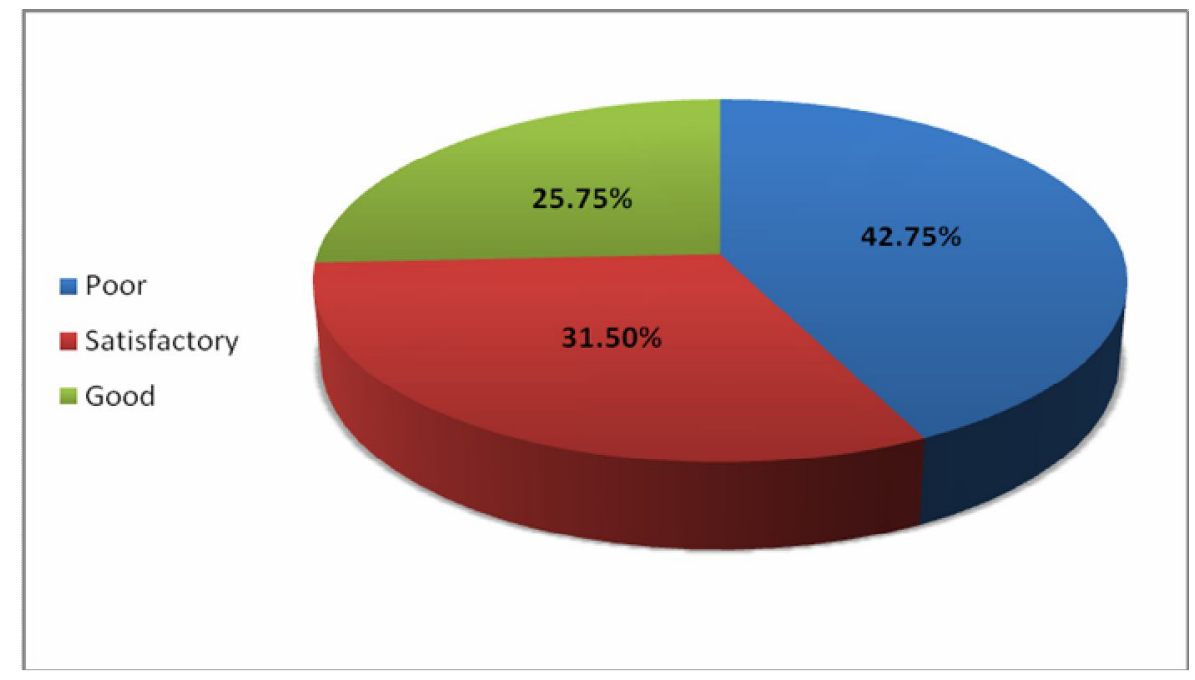

Figure (3): Total score of mothers' knowledge about complementary feeding. 
Complementary Feeding of Breast-fed Children

Table (4): Distribution of mothers regarding to their practices of complementary feeding.

\begin{tabular}{|c|c|c|}
\hline Complementary feeding practices & No $(n=400)$ & $\%$ \\
\hline \multicolumn{3}{|l|}{ Start of complementary feeding by age (months) } \\
\hline$\leq 3$ & 271 & 67.7 \\
\hline $4-5$ & 93 & 23.3 \\
\hline $6 \#$ & 36 & 9.0 \\
\hline \multicolumn{3}{|l|}{ The first food given to your infant } \\
\hline Yogurt & 90 & 22.5 \\
\hline Cerilac- mehalabia \# & 16 & 4.0 \\
\hline Sugary fluids ( yanson- karawia) & 263 & 65.7 \\
\hline Others & 31 & 7.8 \\
\hline \multicolumn{3}{|l|}{ Ways used to introduce first food } \\
\hline Bottle with teat & 171 & 42.8 \\
\hline Spoon \# & 225 & 56.2 \\
\hline Other (syringe) & 4 & 1.0 \\
\hline \multicolumn{3}{|l|}{ Intervals between introduction of each new complementary food } \\
\hline Every day & 45 & 11.3 \\
\hline Every three days to one week \# & 42 & 10.5 \\
\hline Other ( every two weeks or more) & 79 & 19.7 \\
\hline No schedule & 234 & 58.5 \\
\hline \multicolumn{3}{|l|}{ Frequency of daily breastfeeding } \\
\hline Once & 3 & 0.8 \\
\hline Twice & 7 & 1.8 \\
\hline 3-4 times & 47 & 11.7 \\
\hline 5 times and more \# & 343 & 85.7 \\
\hline \multicolumn{3}{|l|}{ Type of food introduced to infant } \\
\hline Specially prepared food\# & 104 & 26.0 \\
\hline Family food & 296 & 74.0 \\
\hline \multicolumn{3}{|l|}{ Number of meals consumed / day } \\
\hline 1 meal only / day & 100 & 25.0 \\
\hline 2 meals/ day & 174 & 43.5 \\
\hline 3 meals/ day & 103 & 25.8 \\
\hline 4 and more /day \# & 23 & 5.7 \\
\hline \multicolumn{3}{|l|}{ Feeding the infant during illness } \\
\hline Breast-feeding only & 264 & 66.0 \\
\hline Breast-feeding, fluids and yogurt only & 78 & 19.5 \\
\hline Increase breast-feeding, vegetable soup, fluids \# & 44 & 11.0 \\
\hline Breast-feeding and the usual food & 14 & 3.5 \\
\hline
\end{tabular}

\# Correct practices. 
Table (5): Distribution of mothers regarding to practices of safe preparation and storage of complementary foods.

\begin{tabular}{||l|c|c||}
\hline \multicolumn{1}{||}{ Practices of safe preparation of foods } & No ( n =400) & \% \\
\hline \hline Timing of mother's hand washing & & \\
Before food preparation only & 65 & 16.3 \\
Before feeding the infant only & 139 & 34.7 \\
Before food preparation and after feeding the infant \# & 196 & 49.0 \\
Timing of infant's hand washing & & \\
Before feeding & 89 & 22.3 \\
After feeding & 199 & 21.5 \\
Before and after feeding \# & 26 & 49.7 \\
Not done & & 6.5 \\
Washing the utensils which your child eats in it & 400 & 100.0 \\
With soap and water \# & & \\
Type of water used for infant drinking \& food & 321 & 80.3 \\
preparation & 79 & 19.7 \\
Tap water & & \\
Boiled water \# & 262 & 65.5 \\
Dealing with left-over & 45 & 11.3 \\
Eat again & 93 & 23.2 \\
Throw it \# & & \\
Store it at refrigerator & 34 & 36.5 \\
Dealing with refrigerated left-over (no=93) & 22 & 23.7 \\
Boiled & 37 & 39.8 \\
Warmed only & & \\
Given cold & & \\
\hline \hline
\end{tabular}

\# Correct practices. 
Table (6): Distribution of mothers according to their behaviors during their infants' feeding.

\begin{tabular}{||l|c|c|}
\hline \multicolumn{1}{|c|}{ behaviors of mothers during feeding } & No ( n =400) & \% \\
\hline \hline How do you know that your child is hungry & 300 & 75.0 \\
Infant crying & 70 & 17.5 \\
Infant request & 30 & 7.5 \\
Mother schedule & 0 & 0.0 \\
Ideal answer all of the above & 389 & 97.3 \\
How do you know that your infant is satisfy & 11 & 2.7 \\
Infant refused food & & \\
Infant sleep & 354 & 88.5 \\
Do you sit with your infant during eating his meal & 46 & 11.5 \\
Yes & & 72.3 \\
Sometimes & 289 & 5.2 \\
Mother's behavior when infant refused the food & 21 & 22.5 \\
The infant left with no food & 90 & \\
Forcing to eat & & 76.5 \\
Encouraging to eat & 306 & 2.5 \\
Methods for encouraging the infant to eat & 10 & 17.5 \\
Nothing & 70 & 3.5 \\
Positive verbalization (talking and singing) & 14 & \\
Playing to him & & \\
Try to give other types of food & & \\
\hline
\end{tabular}

\# Correct practices.

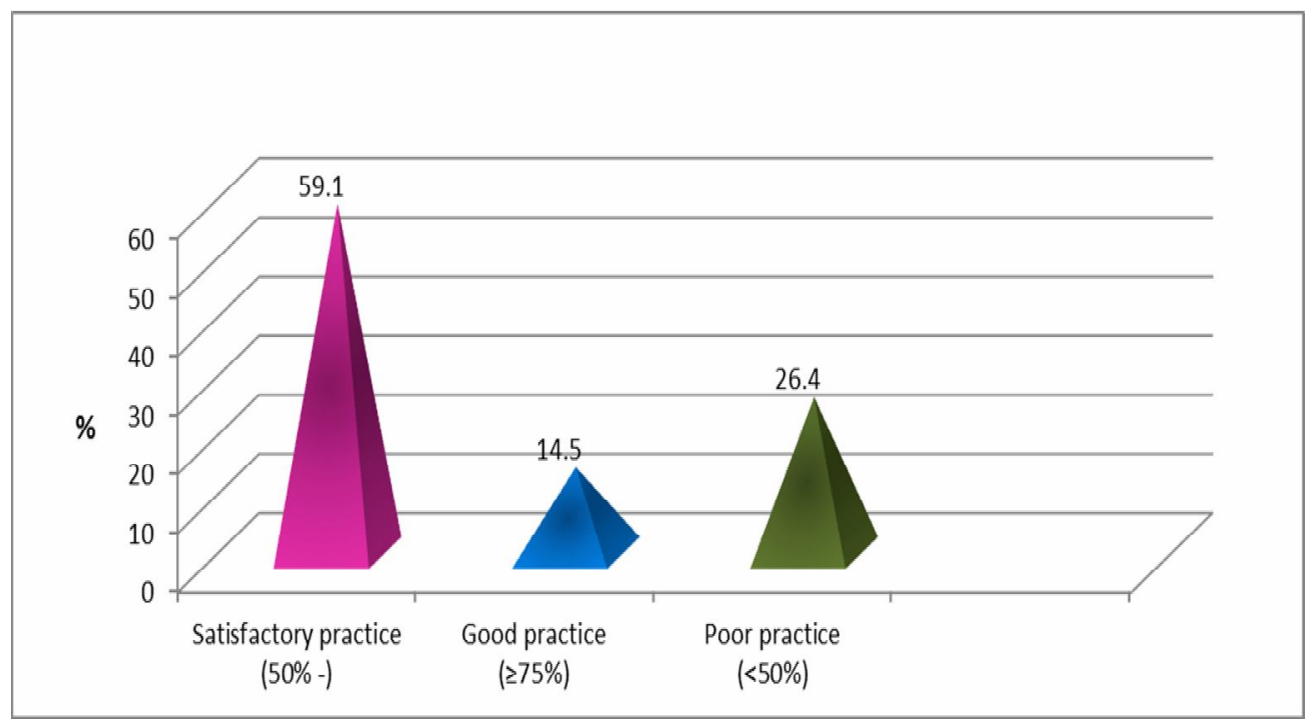

Figure (4): Total score of mothers' practices about complementary feeding. 
Table (7): Correlation between mother' knowledge and practices, with their education and child birth order.

\begin{tabular}{|c|c|c|c|c|}
\hline & \multicolumn{2}{|c|}{ Practice } & \multicolumn{2}{|c|}{ Knowledge } \\
\hline & $\mathbf{r}_{\mathrm{s}}$ & $p$ & $\mathbf{r}_{\mathrm{s}}$ & $p$ \\
\hline Child Birth order & -0.124 & 0.299 & 0.144 & 0.136 \\
\hline Mother's education & 0.037 & 0.715 & 0.017 & 0.904 \\
\hline
\end{tabular}

$\mathrm{r}_{\mathrm{s}}$ : Correlation coefficient

Table (8): The children age at introduction of complementary foods according to mother's socio-demographic variable.

\begin{tabular}{|c|c|c|c|c|c|c|c|}
\hline \multirow[t]{3}{*}{$\begin{array}{c}\text { Mothers' socio-demographic } \\
\text { variable }\end{array}$} & \multicolumn{6}{|c|}{$\begin{array}{c}\text { Infant age at first introduction of } \\
\text { complementary foods }\end{array}$} & \multirow[t]{3}{*}{$\begin{array}{c}\text { Test of } \\
\text { significance }\end{array}$} \\
\hline & \multicolumn{2}{|c|}{$<4$ months } & \multicolumn{2}{|c|}{ 4-<6 months } & \multicolumn{2}{|c|}{ At 6 months } & \\
\hline & No & $\%$ & No & $\%$ & No & $\%$ & \\
\hline Mothers' education & & & & & & & \\
\hline Illiterate & 57 & 64.0 & 26 & 29.2 & 6 & 6.7 & $\mathbf{X}^{2}=10.33$ \\
\hline Primary/preparatory & 69 & 75.0 & 16 & 17.4 & 7 & 7.6 & $\mathbf{P}=0.1116$ \\
\hline Secondary & 117 & 70.0 & 33 & 19.8 & 17 & 10.2 & \\
\hline University & 28 & 53.8 & 18 & 34.6 & 6 & 11.5 & \\
\hline Mothers' occupation & & & & & & & \\
\hline Working & 31 & 59.6 & 16 & 30.8 & 5 & 9.6 & $\mathbf{X}^{2}=2.06$ \\
\hline Not working & 240 & 69.0 & 77 & 22.1 & 31 & 8.9 & $\mathbf{P}=0.356$ \\
\hline Mothers' age & & & & & & & \\
\hline$<25$ & 87 & 73.1 & 24 & 20.2 & 8 & 6.7 & $\mathbf{X}^{2}=3.27$ \\
\hline $25-35$ & 156 & 65.8 & 59 & 24.9 & 22 & 9.3 & $\mathbf{P}=0.5138$ \\
\hline$>35$ & 28 & 63.6 & 10 & 22.7 & 6 & 13.6 & \\
\hline Total & 271 & 67.8 & 93 & 23.2 & 36 & 9.0 & \\
\hline
\end{tabular}

$\mathrm{X}^{2}=$ Chi-Square Test

*: Statistically significant at $\mathrm{p} \leq 0.05$ 


\section{References}

1. Radwan H. Patterns and determinants of breastfeeding and complementary feeding practices of Emirati Mothers in the United Arab Emirates. BMC Public Health. 2013, 13:171. Available at: http://www.biomedcentral.com.

2. National Health Systems Resource Centre. Guidelines for enhancing optimal infant and young child feeding practices. Ministry of health and family welfare government of India, 2013.___ Available at: www.nhsrcindia. or.

3. United Nations Children's Fund (UNICEF). Infant and Young Child Feeding 2012. Available at: iycn@unicef.org.

4. WHO, UNICEF. Baby-friendly Hospital Initiative: revised, updated and expanded for integrated care. Geneva, WHO, 2009.

5. WHO .The optimal duration of exclusive breastfeeding: Report of an expert consultation. World Health Organization, Geneva. 2011.

6. Berhe H. Determinants of breastfeeding practice among mothers of children aged less than 24 months attending governmental maternal and child health clinics in Mekelle town, Ethiopia. Addis Ababa University. College of health sciences, Masters Degree, 2011. (Published thesis).

7. Shi L, Zhang J, Wang Y, Caulfield LE, Guyer B: Effectiveness of an educational intervention on complementary feeding practices and growth in rural China: a cluster randomised controlled trial. Public Health Nutr .2009, 1-10.

8. WHO.Complementary feeding of young children in developing countries: a review of current scientific knowledge. Geneva:WHO;

(WHO/NUT/98.1) 1998: p. 1-227.

9. PAHO/WHO. Guiding principles for complementary feeding of the breastfed child. Washington, DC: PAHO, WHO; 2003: p. 1-37.

10. WHO/UNICEF. Strengthening action to improve feeding of infants and young children 6-23 months of age in nutrition and child health programs. Report of proceedings. World Health Organization, Geneva, 2008.

11. Walker SP, Wachs TD, Gardner JM, et al. Child development: risk factors for adverse outcomes in developing 
Complementary Feeding of Breast-fed Children

countries. Lancet. 2007; 369(9556):145-157.

12. World Bank. Repositioning Nutrition as Central to Development: A Strategy for Large-Scale action. Washington, DC: World Bank; 2006.

13. Jones, G; Steketee, RW; Black, RE; Bhutta, ZA and Morris, SS .How many child deaths can we prevent this year? Lancet; 2003: 362: 65-71.

14. Uauy, R and Solomons, N .Diet, nutrition and the life-course approach to cancer prevention. American Society for Nutrition. J Nutr; 2005: 135: 2934S-2945S.

15. WHO. Complementary feeding: Report of the global consultation and summary of guiding principles for complementary feeding of the breastfed child. Geneva: WHO; 2001: p. 110.

16. Barona-Vilar, C; Escribá-Agüir,V and Ferrero-Gandía, R. A qualitative approach to social support and breastfeeding decisions. Midwifery; 2009: 25 (2): 187-194.

17. Believes Li, R Zhao, Z; Mokdad, A; Barker, L and Grummer- Strawn, L .Prevalence of breastfeeding in the United States: Pediatrics. 2003; 111(5 part 2):1198-1201.
18. HASNAIN, S, MAJROOH $\mathrm{M}$ and ANJUM R. knowledge and practices of mothers for complementary feeding in babies visiting pediatrics outpatient department of Jinnah hospital, Lahore. J Biomedica; 2013: 29 (1): 221-31.

19. Fahmy S, El -Sherbini AF. Determining simple parameters for social classifications for health research .Bull HIPH 1983; 13: 95107.

20. WHO, UNICEF. Development of a global strategy for infant and young child feeding: Report on a WHO/ UNICEF consultation for WHO European Region. Geneva: WHO; (EUR/ 01/ 5018050) 2003: p. 1-57.

21. $\mathrm{Ku} \mathrm{CM}$, Chow SK: Factors influencing the practice of exclusive breastfeeding among Hong Kong Chinese women: a questionnaire survey. J Clin Nurs; 2010:2434-45.

22. El Shafeiy A. Determinants of Exclusive Breastfeeding and Introduction of Complementary foods in Rural Egyptian Communities. Global Journal of Health Science; 2014:6(4).236-44.

23. Nkala, T., \& Msuya, S. Prevalence and predictors of exclusive 
Complementary Feeding of Breast-fed Children breastfeeding among women in Kigoma, region. Tanzania: a community sectional Study. International Breast feeding Journal. 2011. 6-17.

24. Al-Murshed K, Fiala LA, AbdelaGwad ES, Atwa HA. Breast-feeding and complementary feeding practices in Egypt and Kingdom of Saudi Arabia. Bull HIPH. 2004; 34(4): 895912.

25. Salami, L. Factors influencing breastfeeding practice in Edo State, Nigeria. African Journal of Food Agriculture Nutrition and Development. 2006: 6(2), 1-12.

26. Amin, T., Hablas, H., \& AlAbd Al Qader, A Determinants of Initiation and Exclusivity of Breastfeeding in Al Hassa, Saudi Arabia. Breastfeeding medicine. 2011: 6 (2), 59-68.

http://dx.doi.org/10.1089/bfm.2010.0 01 .

27. WHO. Complementary feeding of young children in developing countries: a review of current scientific knowledge. Geneva: WHO; 1998: p. 1-227.

28. Elizabeth W. Patterns and determinants of breastfeeding and

complementary feeding practices in urban informal settlements. BMC Public Health 2011, 11:396.

29. Jelliffe DB, Jelliffe EF: The volume and composition of human milk in poorly nourished communities. A review. Am J Clin Nutr 1999, 31(3):492-515.

30. Trinh L, Rubin G. Late entry to antenatal care in New South Wales, Australia. Reprod Health. 2006; 3: 8.

31. T. S. J. Abada, F. Trovato, and N. Lalu, "Determinants of breastfeeding in the Philippines: a survival analysis," Social Science and Medicin. 2001; 52(1) 71-81.

32. Al-Jassir, MS; El-Bashir, BM; Moizuddin, SK; and Abu- Nayan, A. Infant feeding in Saudi Arabia: mothers attitudes and practices. East Mediterranean Health Journal; 2006: 12 (1-2): 6-13.

33. Al-Shoshan, AA .Factors affecting mother's choices and decisions related to breastfeeding practices and weaning habits. Pakistan Journal of Nutrition; (2007): 6 (4): 318-322.

34. Saxton CF, Nugent PM, Pelikan PK. Mosby's comprehensive review of nursing. $17^{\text {th }} \mathrm{d}$. London Philadelphia Sydney: Moby; 2003.p. 311-313. 
Complementary Feeding of Breast-fed Children

35. Mohammed E, Ghazawy E. Knowledge, Attitude, and Practices of Breastfeeding and Weaning Among Mothers of Children up to 2 Years Old in a Rural Area in El-Minia Governorate, Egypt. Journal of Family Medicine and Primary Care: Medknow Publications2014.

36. Walker RB, Conn JA, Davies MJ, Moore VM. Mothers' views on feeding infants around the time of weaning. Public Health Nutr. 2006; 9: 707-13.

37. Kishore K. Knowledge, Attitude and Practices of weaning among mothers in Gulbarga, MD thesis; Department of Pediatrics, MR Medical College, Gulbarga, Ranjiv Gandhi University of Health Sciences; Karnataka, Bangalore. 2008. pp. 1-71.

38. Severi S, Bedogni G. Effect of cooking and storage methods on the micronutrient content of food. Eur $\mathbf{J}$ Cancer Prev 1997; 65(Supp.1): 521-4.

39. The Pan American Health Organization. Promoting health in the Americas. The WHO golden rules for safe food preparation. [About 3 pages]. Available at: http://www.paho.org/English/DD/PE D/te-gold.htm.

40. Fouda LM. Role of mothers in providing safe food for their preschool children in Alexandria. Thesis Dr PH, Alexandria, High Institute of Public Heath, University of Alexandria 2000.p. 94-108.

41. Wansi E, Matango D, Maganga E, Banda E, Msiska T. Child health: Community IMCI Baseline Survey in Malawi. 2000. UNICEF WHO MALAWI GVT. p: 1-116.

42. Demographic and Health Surveys. Measure DHS. Introducing complementary foods to infants in Central Mali: Research Summary. [About 3 pages]. Available at: http://www.measuredhs.com/aboutsur veys/qualitative-research.cmf. [Retrieved on: 15 Jan 2006].

43. WHO. Community-based strategies for breast-feeding promotion and support in developing countries. Geneva: WHO; 2012: p. 1-28. 
Complementary Feeding of Breast-fed Children

44. Abd El-Rahman HA, Mohamed TA, Shoulah AR, EL Moslamani AM. Beliefs and traditional practices affecting nutritional status in infancy at Kaliobia Governorate. Egypt J Community Medicine 2004; 12(2):81-7. 